\title{
Giant thoracic aorta aneurysm causing airway and esophagus stenosis
}

\author{
F. Inzirillo1, G. Giorgetta1, S. Tiberi², C. Della Pona1
}

\section{Case report}

We present a case of a 85 year old male patient that was hospitalised in our Thoracic Surgery department with dyspnea and dysphagia in known COPD, renal failure and thoracic aorta "twin" aneurysm [1]. Blood gases examination showed significant respiratory failure $\left(\mathrm{PaO}_{2}: 56,1 ; \mathrm{Pa}-\right.$ $\left.\mathrm{CO}_{2}: 49,8 \mathrm{pH}: 7,231\right)$. The patient was in an obliged semi-orthopneic position and was extremely weak (weight $43 \mathrm{Kg}$; height $171 \mathrm{~cm}$ ) because of dysphagia. He was unable to eat solid food for about 20 days. The CT scan (without enhancement due to renal failure), showed a giant thoracic aorta aneurysm causing distal airway and oesophageal stenosis (fig. 2). Cardiovascular Surgery evaluation ruled out any surgery options because of size of the aneurysm, general clinical conditions and age of the patient. We performed, in emergency, rigid broncoscopy and Y-stenting of distal airway (siliconic Y-stent, 16-13-13) (fig. 3, 4) and placement of naso-gastric tube by gastroscopy obtaining re-feeding and total recanalisation of the distal tract of trachea and right main bronchus and partial recanalisation of left main bronchus. We recorded a significant improvement of respiratory function $\left(\mathrm{PaO}_{2}: 63,6 ; \mathrm{PaCO}_{2}\right.$ : 36,$2 ; \mathrm{pH}:$ 7,432). The patient retained a significant difficulty dysphagia for solid food and was discharged from hospital 6 days after the endoscopic supportive treatment. Two post operative endoscopic controls showed the perfectly positioned stent with sufficient increase in the breathing space but the patient suddenly died two months after first rigid broncoscopy due to

Fig. 2. - CT scan showing ab estrinseco stenosis of distal airway and oesophagus.

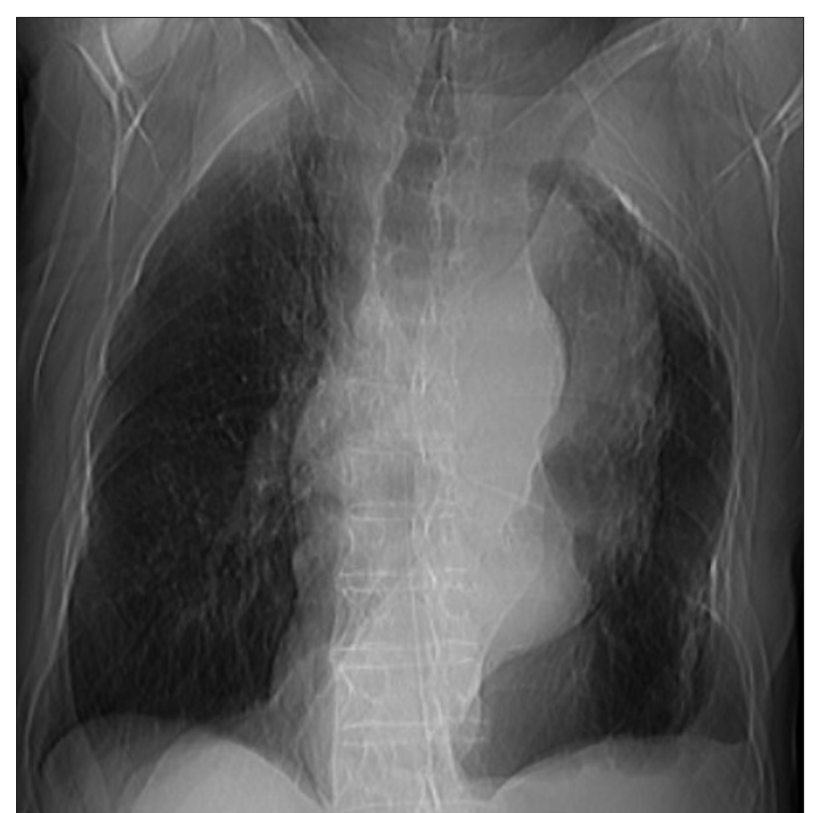

Monaldi Arch Chest Dis 2012; 77: 3-4, 145-146

Key words: Aneurysm, Thoracic aorta, Tigid bronchoscopy, Airway stent, Oesophageal stent

1 Department of Thoracic Surgery,

2 Department of Phtisiology; Morelli Hospital, AOVV, Sondalo (SO), Italy.

\section{Corrispondence:}

Dr. Francesco Inzirillo, Department of Thoracic Surgery, Morelli Hospital, AOVV, Via Zubiani 33, 23035 Sondalo $(\mathrm{SO})$, Italy; e-mail: francescoinzirillo @gmail.com

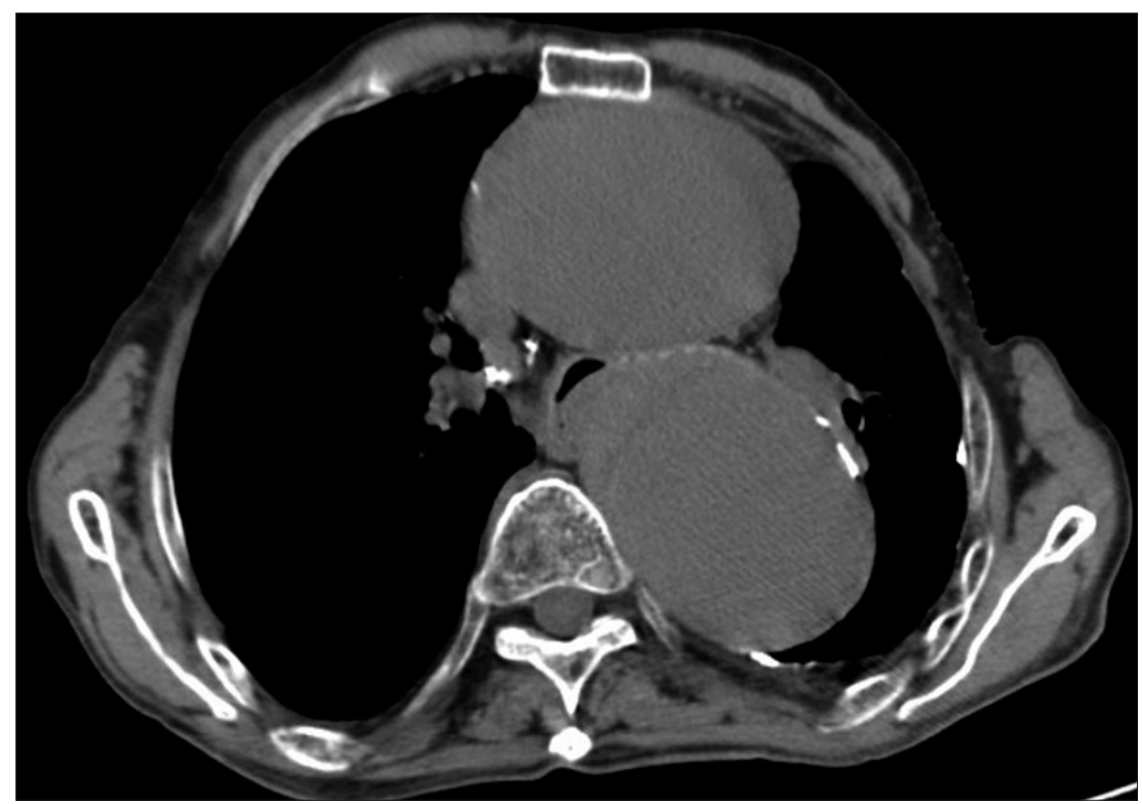




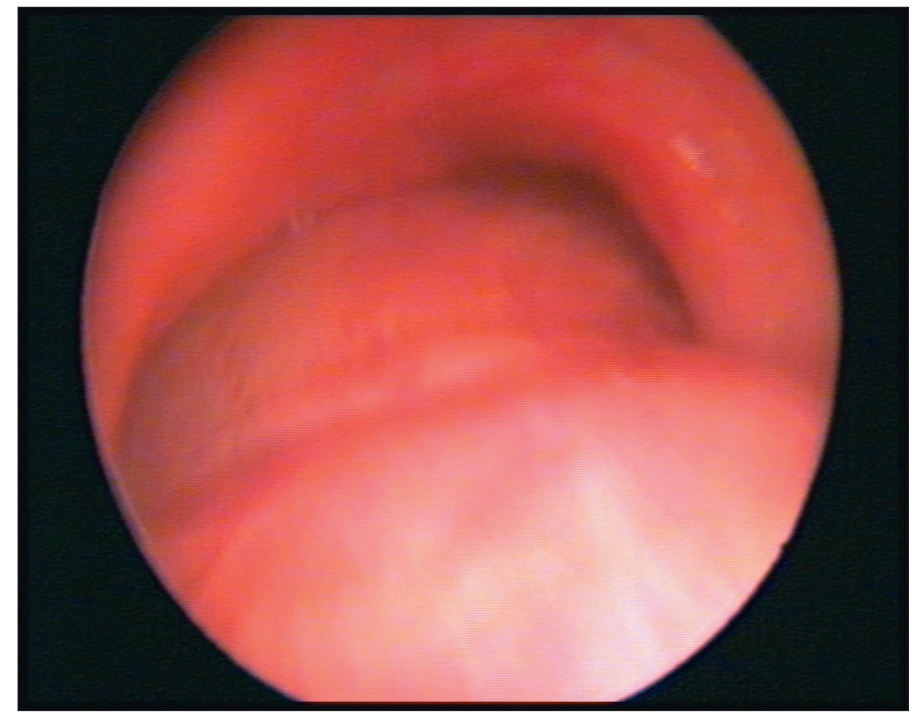

Fig. 3. - Rigid broncoscopy showing distal airway stenosis.

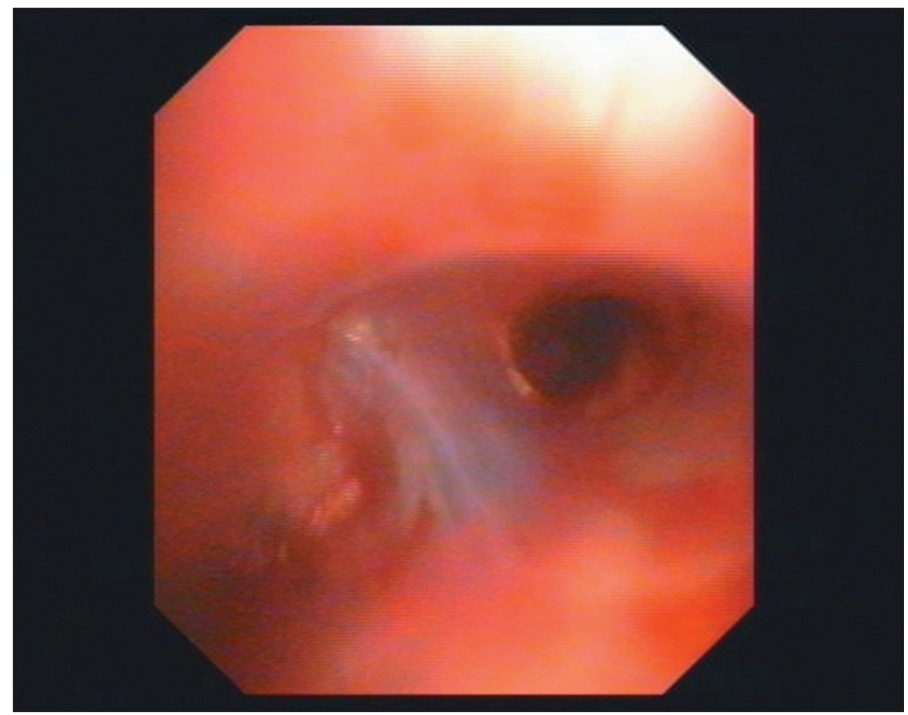

Fig. 4. - Distal airway Y stenting. rupture of the aneurysm. In conclusion, It is essential to recognise that thoracic aortic aneurysm may present as an acute obstruction of the central airways [2] and oesophagus that can be treated with resolution of the cause of compression, if possible, or palliation as we described.

\section{References}

1. Totaro P, Zattera G, D'Armini AM, Viganò M. A giant "twin" aneurysm of the thoracic aorta. $J \mathrm{Am}$ Coll Cardiol 2011; 57: 2205.

2. Milman N, Jensen PR, Laoutliev BN. Aneurysm of the thoracic aorta causing fatal tracheobronchial obstruction. J Bronchol 2002; 9: 200-203. 